\title{
FRAGMENTATION IN CONTEMPORARY PSYCHOLOGY: A DIALECTICAL SOLUTION
}

\author{
Sanford L. Drob, Ph.D.
}

This article was originally published in The Journal of Humanistic Psychology, Volume 43, No. 4, Fall 2003, 102-123, (C) 2003 Sage Publications.

Abstract: The author proposes a dialectical/realist solution to the problem of multiple paradigms in psychology. Specifically, he argues that theoretical models in psychology are akin to various two-dimensional maps of the three-dimensional, spherical earth. In cartography each projection serves as a complementary, if ultimately inadequate, perspective on the whole, in a context where a "total perspective" is impracticable. Like such cartographic projections, each paradigm in psychology (biological, behavioral, cognitive, systems, psychoanalytic, phenomenological, etc.) necessarily distorts certain aspects of human mind and behavior while being accurate regarding others which are, in turn, distorted by other points of view. The author argues that the various paradigms in psychology emerge as a result of (combinations of) answers to fundamental problems in the philosophy of psychology. These are the problems of: (1) free will vs. determinism, (2) materialism vs. phenomenology, (3) reductionism vs. emergent properties, (4) public vs. private criteria for psychological propositions, (5) the individual vs. the system as the basic unit of inquiry and description, (6) facts vs. interpretations (hermeneutics) as the datum of psychology, and (7) knowledge vs. unknowability as a basic methodological assumption. Psychologists have been mistaken in their assumption that the oppositions or "antinomies" represented in these problems must lead to mutually exclusive ideas. Instead, the polarities (e.g. free will and determinism) are better conceived dialectically as complementary, interdependent ideas; each idea only making sense by assuming the truth of its presumed contrary. When the complementarity of these contraries is recognized the problem of multiple paradigms and factionalization in psychology is cast in a new light. Psychologists can continue to flesh out details in their various maps, secure that they are contributing to the exploration of a (dialectically) integrated whole.

At the close of its most distinguished century, psychology appears to be no closer to resolving the issues that divide it than in the past. It is perhaps symptomatic that the disorders of identity, the borderline pathologies, and multiple personality disorder (recently renamed dissociative identity disorder) should draw so much attention from psychologists at a time when the identity of their own profession is itself open to such question.

A growing literature detailing the problem of psychology's fragmentation has emerged over the past two decades (Baars, 1985; Bower, 1993; Dixon, 1983; Drob, 1987; Giorgi, 1985; Koch, 1981; McNally, 1992; Rychlak, 1993; Staats, 1981, 1986, 1991). Indeed, there is nearly as much fragmentation amongst those who propose solutions to psychology's disunity as there is fragmentation within the field itself. Proposals to unify psychology range from those which reaffirm positivism (Staats, 1981, 1986, 1991 ) to 
those who would have theoretical debate in psychology settled on hermeneutic (Martin, 1997), or even moral grounds (Kristensen, 1997).

Nowhere is the fragmented state of psychology more evident than in the clinical field. In a previous publication I outlined what I regarded to be the six major paradigms within contemporary clinical psychology: the biological, the behavioral, the cognitive, family-systems, psychoanalytic, and existential-interpersonal approaches (Drob, 1987). I argued that these perspectives could be distinguished from one another on the basis of their (1) assumptions regarding the "deep structure" of psychopathological phenomena, (2) specific theories of psychopathology, (3) treatment modalities, (4) value orientation and treatment goals, (5) historical antecedents and, (6) philosophical foundations.

I also outlined six options for the resolution of psychology's factionalized state. One could (1) opt for a form of reductionism, attempting to translate or "reduce" the propositions of the other theories to one's own, (2) hold that the various theories were commensurable with one another and therefore subject to selection through scientific tests, (3) hold that, like so many different religions, they were relative to one's point of view and, therefore, incommensurable, (4) choose some form of eclecticism, (5) hold that the different theories were meant to explain different states and phenomena, and were therefore referentially distinct, or (6) hold out for an ultimate synthesis, a super-theory which would encompass the findings of all the different schools and either synthesize, or obviate the need for, the multiple points of view. Since that time I have become aware of theoreticians who (7) believe that traditional disputes within psychology should be resolved on moral or other non-scientific grounds, and (8) who hold that fragmentation within psychology is itself a welcome sign, reflecting the essential undecidability, elusiveness and fragmentation within all language and theory.

What is psychology to do? More importantly, what are the "consumers" of psychology to do, for example, in response to the barrage of different therapies all purporting to treat the same supposed condition? These are serious questions, which have been largely addressed by Staats $(1981,1986,1991)$ from a positivist point of view. More recently, Rychlak (1993) has proposed a "principle of complementarity" adapted from quantum physics, which sees physical, biological, social, and psychological perspectives as independent but complementary bases for a positivistic psychological science. In this paper I propose a theoretical foundation for complementarity in psychology. I am in agreement with those who hold that a unique solution to psychology's fragmentation is impossible, and who ultimately embrace the problem inherent in psychology's "multiple perspectives". However, I do not hold that such a multi-perspectivist position inevitably leads us to a radical social constructivism and relativism. I believe that a dialectical approach to the various paradigms in psychology will enable us to maintain a multiple perspective but realist position regarding the nature of the mind.

\section{Dialectics}

The term "dialectic" has a long and equivocal history. Over the centuries it has been used variously to refer to "analysis by division," "refutation by examining 
consequences," formal logic in general, and even "sophistical" reasoning. Socrates' dialectic involved a prolonged examination of an original thesis that resulted in the drawing of a consequence which refuted that thesis, and it is this procedure which informs Hegel's dialectic, in which concepts are shown to imply their contraries in the service of a higher unity. It is this Hegelian sense of dialectic that will be of service in my own argument. I will attempt to show that when pressed to their logical conclusions the very concepts that underlie diverse paradigms in psychology actually imply contrary ideas that support paradigms that the original concepts were meant to exclude. Further, I will argue that only by maintaining the truth of both notions in certain pairs of presumably contrasting ideas about the mind will we be able to attain a coherent and comprehensive account of our subject matter.

However, before presenting my "formal" argument I will show, by way of analogy, how such a dialectical argument is going to work, and then apply this argument to a problem that is much simpler than providing a theory of the mind, i.e. providing a two dimensional map of a three dimensional world.

\section{A Matter of "Perspective"}

A typical response to the fragmentation within contemporary psychology is that each school views psychopathology from a particular "perspective" or "point of view". Biological psychology, for example, is said to view psychopathology from the perspective of genetics and the neurophysiology of the brain, whereas systems theory is said to view the same phenomenon from the perspective of its function within the family and the wider culture. It is very important to realize, however, that the word "perspective" has a very different sense when it is used with reference to an object whose ultimate nature is a mystery as compared to its more common use, for example, in drawing and painting, where the object is completely known and understood but simply approached or painted from one or another "side" or "point of view". It is by no means clear what "psychopathology" (or the mind, for that matter) is in and of itself. Indeed, by adopting different solutions to the nature of the "deep structure" of the mind, it is sometimes said that the various psychological schools actually define their object of inquiry in different ways.

A solution to the problem of "perspectives" in psychology would be forthcoming if it could be shown that our inability to understand the "ultimate object" results from a failure to generate the appropriate meta-theory of the mind. And indeed, there are certain situations, outside psychology, in which apparently incompatible descriptions of a single object turn out to be compatible when we shift to a superior point of view or "metaperspective". An example of this is what might be called the New York-Buenos Aires moon paradox. Two observers, one in New York, the other in Buenos Aires, observing the moon simultaneously on any given evening will, if they compare their observations, realize that while they are both seeing the same portion of the moon illuminated, that portion is inverted left to right and upside down in Buenos Aires as compared to New York. Further, the moon appears in the Northern sky when viewed from Buenos Aires and in the Southern sky when viewed from New York. This last fact provides us with a clue to the resolution of the paradox, for when we move from New York to Buenos Aires 
the observed position of the moon has effectively traversed 80 degrees of arc in the sky and in so doing has, in effect, rotated itself relative to the viewer so that it appears upside down and inverted right to left. The apparent paradox of these "contradictory perspectives" is resolved once we recognize the spherical nature of the geometry that controls the positions of objects on the "celestial sphere". The paradox only exists when we continue to view the earth naively as a flat plane and the moon as on object in a Euclidean sky. Further, the resolution of the paradox forces us to comprehend that when we travel from New York to Buenos Aires it is not the moon but we ourselves who have been turned upside down!

Another example of an apparent paradox, one that also depends upon the distinction between planar and spherical geometry, can be called the "Mercator-Polar Map Paradox". As children we have all seen, and been puzzled by, maps that represent the entire world alternatively as a rectangle or as two circles on a flat, two-dimensional, plane. As children we wondered how both of these seemingly incompatible representations could each depict the world in its entirety. The clue to the paradox, of course, is that each is an attempt to do something which is virtually impossible, i.e. to represent on a two-dimensional surface (a map) what is, by nature, a three dimensional phenomena, the globe. Once we compare the maps to the globe we can see how it is, and from what perspective, they were constructed and thereby comprehend not only the possibility, but also the advantages and the limitations of each.

Our two paradoxes are instructive inasmuch as they each provide us with an example of the resolution of an apparent contradiction in our experience or representation of reality through a process of gaining a meta-perspective which explains the appearance of the phenomena from the original, apparently incompatible, points of view. In the map paradox, for example, a contradiction in two dimensions is resolved once we view the world from three.

Perhaps a similar line of reasoning can be applied in psychology and the philosophy of mind. Is there a meta-perspective that we can gain which will resolve the apparent incompatibilities amongst the various psychological schools? Is there some theory which will enable us to grasp the various descriptions of human behavior, from psychoanalytic, behavioral, existential, biological, cognitive and systems perspectives as variations or distortions upon a superior point of view. In other words, can we lay hold of the globe for which each of these perspectives in psychology and psychiatry is merely a distorted two-dimensional map?

\section{Seeing the World in "2 D"}

A certain advantage is to be gained with respect to our dilemma if instead of attempting to confront it head on in all its complexity, we constrict our point of view and attempt to understand how we might resolve a similar dilemma if we were more limited in our powers of observation and experience than we actually are.

Consider for the moment a hypothetical situation, a "possible world", in which individuals who could only experience the world in two dimensions were provided with 
Mercator (rectangular) and Polar (dual circular) maps of our three dimensional world. Not having any experience with three dimensional "globes" such individuals would be forced to construct a model of the 3D world on the basis of their two dimensional experiences. They might construct various maps and regard them as "theories" or "models" of the earth and seeing that within their two dimensional experience these maps were apparently mutually exclusive, they might hold their various models to be contradictory or completely incommensurable. For them, the true nature of the "globe" would be as much a mystery as the true nature of the mind is for us.

Given the fact that such individuals who can only see the world in " $2 \mathrm{D}$ " have no possible opportunity of reconciling their models via an experience of the world in three dimensions, we might ask what would be their best course of action with respect to their maps or models. Would it be best for them to somehow select one and regard the other as incorrect (open competition)? Or would it be better for them to attempt to show how one model (map) could be reduced (mapped on) to the other without loss of meaning (reductionism)? Perhaps they might hold that the two maps were incommensurable, each being true for the cartographer who created it but false or irrelevant to cartographers who created or "believed" in the other maps (relativism). Another option would be for them to use one map on some occasions and the other map on other occasions, choosing, in each instance, the map that seemed to" work" best under the circumstances (eclecticism). Finally, they might spend their energies in an attempt to create a new map, one that would synthesize the best features of the Mercator, Polar and other global projections (Ultimate Theoretical Synthesis). We might ask ourselves, however, if any of these options would bring them any closer to the "truth", or whether, in their efforts to eliminate (or in the case of eclecticism, ignore) the apparent incompatibilities between their two maps or models they sought a premature or misleading theoretical closure.

What, we might ask, would occur if the 2D people took a dialectical approach to their cartographic dilemma? They might, in a Socratic manner, get the advocates of the Mercator projection to acknowledge that two individuals on the opposite east and west extremes of their map are actually in the same place as opposed to being at opposite ends of the world as the Mercator projection would imply. They could then argue that this very contradiction in the Mercator map can only be resolved by adopting the dual polar projections in which the continuous "circular" nature of east and west is represented. A similar argument could be made by advocates of the Mercator map to elicit contradictions in the dual polar map (e.g. that this map seems to imply "two worlds") which could only be resolved by adopting something like the (single) rectangular projection. The results of such critical examinations of "competing cartographic theories" would reveal each map, each theory, to be incomplete without the other, and that adopting both perspectives is a necessary step in providing an adequate description of the world. Further analysis would also show that these two projections hardly exhausted the number of fruitful cartographic possibilities, and that an indefinite number of perspectives (or maps) could be generated, each contributing some new insight into the three dimensional world which had hitherto not been provided by any of the others. 
In the absence of a concept or experience of a three-dimensional world, it would then appear that the best, "truest", alternative would be for the "2D people" to hold that both maps (and any other projections they may possess), as different as they are, are valid and true? Such a dual or "multi-perspectivist" would come closer to describing a three dimensional space than any of the other theoretical procedures. Wouldn't it then be best to simply say that the earth is an entity that can be described both with a rectangular model and a dual circular model (as well as via an indefinite number of other two dimensional models)? Such a position would have several distinct advantages. It would, for example, enable the $2 \mathrm{D}$ people to navigate the world much more accurately and efficiently, utilizing the Polar projection near the poles and the Mercator projection closer to the equator (but then using the Polar projection again to show how the two opposite ends of the Mercator projection actually meet). In doing so the two projections would allow them to arrive at the valid conclusion (within the confines of their own possible experience) that the earth was a plane which is nevertheless circular, inasmuch as it ultimately returns to itself, its end being the same as its beginning. In short, the denizens of a two dimensional world would fair better in maintaining the truth of each of their world models than they would if they were to adopt any of the other procedures (reductionism, relativism, theoretical synthesis) I have outlined, the very procedures which, as we have seen, many have adopted with respect to psychological models and paradigms.

Some of the 2D people who held that both maps were "true" might in fact be accused of speaking a mystical, paradoxical language, or of violating the "law of noncontradiction". Some of the more venturesome amongst the $2 \mathrm{D}$ people might infer that there is indeed a "true" 3D world, of which their own two-dimensional experience is but an imperfect reflection. Such a "true" world would likely be posited by them as reconciling the antinomies of their own, and explaining why each of their apparently contradictory maps were "true". However, the accusations that such a view is "mysticism" would hardly be apt: the view only appears paradoxical or mystical because it attempts to describe a reality that lies outside the bounds of the 2D people's experience. From our, "3D" point of view, we can understand why their multi-perspectivist account is precisely the one that is demanded by both reality and reason.

Consider the possibility that with respect to the human mind we are in the identical, or at least analogous position, to the 2D individuals I have described above.

\section{A Synoptic View of the Mind?}

Like our 2D people who have perspectives upon a three dimensional earth but no experience of the globe with which to compare and adjudicate their perspectives, we have perspectives on the "mind" without having a synoptic view of the mind itself.

Since we do not have a synoptic view of the mind as a whole we must attempt to construct a theory which approaches synopsis from within the structure of our own epistemological limitations. However, we must first recognize that each of our maps, each of our constructions, the biological, behavioral, cognitive, psychoanalytic, existential and systems, to take the major examples, purport to, and in some sense do, 
provide a complete view of the human mind, much as each of the cartographic projections of the globe provide a "complete" map of the earth, from a given point of view. And like the cartographic projections, each of the major theories of the mind will end up distorting certain of the phenomena under its purview. Thus while it is possible to provide a neuro-biological theory of "normal mourning" or a psychoanalytic theory of "epilepsy", to take two examples, such theories, are likely to create more distortion than illumination, much like an Equatorial Mercator projection or dual Polar projections are likely to cause more distortion than illumination with respect to the poles and equator of the earth respectively.

In general, it is my view that the various schools or paradigms within psychology, while appearing to be mutually exclusive, are actually completely interdependent. Each paradigm cannot be provided a full sense unless we assume the truth of what we normally regard to be its contrary. However this mutual interdependence can only be demonstrated through an examination of the deep philosophical structure of the various theories, i.e. by examining the philosophical assumptions that underlie biological, behavioral, cognitive, psychoanalytic and the other paradigms in psychology. It is these underlying assumptions that a dialectical analysis will show to mutually correcting and interdependent, much like the various two dimensional maps of a three dimensional world. Further, it is only through a multiplicity of paradigms and perspectives that we can ever hope to arrive at a "full dimensional" synoptic view of the mind.

\section{Antinomies of the Mind}

In order for us to appreciate how the different paradigms within psychology complement one another like the different cartographic projections of the globe, it is necessary for us to gain some more clarity with respect to the philosophical differences that underlie the various psychological schools. Those who have reflect upon the problem realize that underlying the fragmentation within contemporary psychology are a series of polarities (Kimble, 1984), philosophical antinomies, or apparent contradictions in our view of the nature of the mind. Several of these antinomies have been known to philosophers at least since the time of Kant, others have emerged in more recent times.

Let us then, in somewhat Kantian fashion, articulate several of the apparent contradictions in psychology in some detail. Each of them condenses a considerable body of philosophical as well as psychological research and reflection into apparently contradictory (or at least contrary) statements about human experience and behavior.

(1) It would seem from the perspective of our own subjectivity (and from the demands of morals and ethics) that many human actions are freely chosen and thus the responsibility of the actor. However, a scientific view of the world suggests that all human behavior is subject to the same causal laws which govern the physical world. Hence, human behavior is both free and not free (free will vs. determinism).

(2) Common and scientific sense dictates that we live in a world of objects and things, which in their existence and nature are completely independent of the human mind. However, reflection prompts us to realize that we can neither name, describe, nor even 
experience any of these presumed objects except under the aegis of a category, kind, language, or idea, the natures of which are themselves apparently dependent upon the human mind. Thus, the world is both completely independent of and completely dependent upon the mind (objectivism vs. constructivism).

(3) Natural science seems to dictate that the properties of the molar phenomena of mind are completely dependent upon and explicable on the basis of molecular units. However, the phenomenology of such "mental objects" as thought, consciousness, and will, as well as the complexities of human behavior, leads us to the conclusion that the mind is sui generis, that its peculiar properties cannot be explained on the basis of underlying biology and physics (elementism vs. holism).

(4) Experience suggests that we each have privileged, introspective access to our own thoughts, states of mind, moods, and other mental states. However, observation and reflection upon the way in which we learn and utilize so-called "mental terms" suggests that we do so on the basis of publicly observable situations and behaviors. Hence, the subject matter of psychology is and is not the inner experience of the human mind (public vs. private criteria).

(5) It would seem from introspection and general observation that such mental entities as thought, perception, anxiety, depression, schizophrenia, etc., (indeed, the entire subject matter of psychological research and inquiry) are wholly contained within the individuals to which these terms are applied. However, an analysis of how these and other terms are used suggests that they invariably involve a relationship between two or more persons and a society or sub-society of "speakers" who have not only tacitly agreed to use this language in a certain, specified way, but who, in effect, have constructed the "mental entity" as part of their language and culture. Hence mental attributes are both within an individual mind and the society within which the individual dwells, i.e. in the system (individualism vs. collectivism).

(6) Common, scientific sense dictates that the events that determine human behavior are "facts" which operate invariably, in the same manner that efficient causes operate in the natural world. However, both research and reflection suggest that the "facts" of human experience are only "facts", and the causes of human behavior are only "causes", insofar as they are conceived and interpreted by a human subject. Hence, psychology does and does not deal with the factual basis of human behavior (factualism vs. hermeneutics).

(7) It would seem that the entire cosmos, including the human mind, is a rationally ordered system that will be progressively subject to the conquest of human theory and knowledge. However, the existence, nature, and ultimate value and significance of the world and humanity, present themselves as insuperable mysteries which are essentially impenetrable to human reason. Thus the subject matter of psychology is both (potentially) completely knowable and essentially unknown (knowledge vs. the unknown). 
S. Drob Fragmentation in Contemporary Psychology:

Journal of Humanistic Psychology, Volume 43, No. 4, Fall 2003, 102-123. (C) 2003 Sage Publications.

Each of these antinomies operate tacitly within contemporary psychology and one might, in fact, derive the existence of various psychological and psychiatric "schools" by noting the position which they take on these six philosophical questions.

\section{"Possible" and "Actual" Psychological Schools}

By enumerating our seven antinomies and articulating the philosophical views which are derived through the adoption of one or the other of the two "poles" within each of them we are in a position to map out the system of potential psychologies. We can then locate the actual schools of psychology and psychiatry within that map or system. The seven basic antinomies and the philosophical positions they engender are outlined in Table 1. I have included in parentheses abbreviations for each of the various philosophical positions, as they will be useful in the discussion to follow.

\section{Table 1}

1) Determinism Vs. Free Will (Det1 vs. Fr2)

2) Objectivism vs. Constructivism (Ob1 vs. Con2)

3) Elementism vs. Holism E11 vs. Ho2)

4) Public vs. Private mental criteria (Pu1 vs. Pr2)

5) Individualism vs. Collectivism (Ind1 vs. Col2)

6) Factualism vs. Hermeneutics (Fac1 vs. Her2)

7) (Complete) Knowability vs. (an essential) Unknown (Kn1 vs. Un2)

We can readily imagine psychological theories that hold as axiomatic several of these philosophical points of view. While, unlike Kimble (1984) I have not put these propositions to empirical survey or tests, we can infer, for example, that neuro-biological psychologists, who hold that all mental events are ultimately neuro-physiological events which transpire in the brain, are likely to be deterministic, objectivistic, and elementistic. In addition, they are likely to hold that such mental events as thought or depression are, at least potentially publicly observable, that the locus of psychological phenomena is in the individual, that facts irrespective of the interpretations the mind places upon them are of ultimate importance in psychology, and that the nature of the human mind is, at least potentially, completely knowable. Conversely, existential psychologists hold many philosophical positions that are diametrically opposed to those above. They are likely to affirm free will, the existence of emergent properties, the ultimate privacy of human experience, the importance of hermeneutics (interpretation) and the ultimate unknowability of basic issues regarding the psyche of man.

I have divided the philosophical positions discussed above into two basic groups, according to what many would regard as their most natural affinities or logical coherences. Thus, those positions whose abbreviations I have characterized with the numeral " 1 ", determinism, materialism, reductionism, public criteria, individualism, factualism and knowability cohere together in what one might call a natural scientific view of the mind. On the other hand, the positions whose abbreviations I have labeled 
S. Drob Fragmentation in Contemporary Psychology:

Journal of Humanistic Psychology, Volume 43, No. 4, Fall 2003, 102-123. C 2003 Sage Publications.

with the numeral " 2 ", freedom of the will, idealism, "private criteria", collectivism, hermeneutics, and "unknowability" show a certain coherence in constituting a humanistic point of view. Between these extremes are a wide variety of intermediate positions which adopt some of the philosophical positions of each of the two more radical perspectives. Table 2 provides a summary analysis of various psychological theories according to the scheme I have just described:

Table 2

\begin{tabular}{|c|c|c|c|c|c|c|c|}
\hline Biological Psychology & Det1 & Ob1 & El1 & $\mathrm{Pu} 1$ & nd1 & Fac1 & Kn1 \\
\hline Socio-biological & Det1 & Ob1 & El1 & Pul & Col2 & Fac1 & Kn1 \\
\hline Behaviorism & Det1 & Ob1 & Ho2 & $\mathrm{Pu} 1$ & Ind1 & Fac1 & $\mathrm{Kn} 1$ \\
\hline Family Systems & Det1 & Ob1 & Ho2 & $\mathrm{Pu} 1$ & Col2 & Fac1 & $\mathrm{Kn} 1$ \\
\hline "Common Sense" & $\operatorname{Fr} 2$ & Ob1 & Ho2 & $\operatorname{Pr} 2$ & Ind1 & Fac1 & Kn1 \\
\hline Cognitive Psychology & Det1 & Con2 & Ho2 & $\operatorname{Pr} 2$ & Ind1 & Her2 & Kn1 \\
\hline Psychoanalytic I * & Det1 & Ob1 & Ho2 & $\operatorname{Pr} 2$ & Ind1 & Her2 & $\mathrm{Kn}$ \\
\hline Psychoanalytic II. & Det1 & Con2 & Ho2 & $\operatorname{Pr} 2$ & Ind1 & Her2 & Uk2 \\
\hline Existential & Fr2 & Con2 & Ho2 & $\operatorname{Pr} 2$ & Ind1 & Her2 & Uk2 \\
\hline Analytical/Archetypal & Fr2 & Con2 & El1 & $\operatorname{Pr} 2$ & Col2 & Her2 & $\mathrm{Uk} 2$ \\
\hline
\end{tabular}

I have highlighted six (or seven) major psychological schools and have included two more schools (socio-biological and archetypal) which have achieved a renewed prominence in recent years. The last of these, Analytical/Archetypal or Jungian, psychology is particularly noteworthy for its embodiment of a philosophy which is, in every respect, antithetical to the "scientism" which is manifest most clearly in the neurobiological theories of mind. While Jung insisted that his approach was purely descriptive, and in that sense, scientific, a close examination of his writings and practice suggests that his psychology, by virtue of its philosophical assumptions, is far closer to other more "humanistic" points of view. ${ }^{\text {i }}$

I have included the notion of a psychology based upon "common sense" (what is often referred to as "folk-psychology") in order to indicate that the various psychological 
models that have received attention in western society vary in the number and strength of the assumptions that they share with the "man or woman on the street". That this hypothetical man or woman on the street often seems to hold views which psychologists find incompatible (i.e. between freedom of the will and materialism) does not trouble the common man.

It is obvious both on logical and historical grounds that there are many more psychological theories than those I have enumerated in Table 2. Our seven antinomies yield the potential for over 100 combinations of philosophical positions, many of which are not represented amongst contemporary psychological theories.

As is evident from our discussion, psychology has generally attempted to resolve the question of multiple maps or perspectives by assuming or adopting specific solutions to the questions raised by the apparent contradictoriness of the human mind. I have questioned, however, whether there might not be a solution, on the analogy with our map-making dilemma, which, instead of advocating one map or another of the human psyche, utilizes them all in an effort to lay hold of the mind itself.

\section{The Dialectical Integration of Perspectives in Psychology}

In this section I intend to conduct a dialectical analysis of the ideas I have outlined as the "deep structures" of the various paradigms in psychology. What I hope to show in a preliminary way is that each of the various schools or models of psychology, like so many seemingly complete but ultimately inadequate maps of the world, each break down and ultimately require the other models in order to provide anything like a synoptic view of the human mind.

Before discussing the dialectical integration of the perspectives in psychology it is important to point out that although I am in sympathy with Kitcher's (1992) vision of an interdisciplinary approach to the mind, I am in agreement with Rychlak (1993) that the procedure of adopting one or another position with respect to the various philosophical antinomies I have described is essential for there to be cumulative progress in the psychological sciences. In constructing a map one must (at least initially) take a definite perspective and stick to it, otherwise one ends up with only disorder and confusion. We might argue that because of the radically different assumptions at the core of the various psychological schools, several or a number of different psychological sciences have developed, each with its own body of knowledge, research criteria, professional organs, and methods of psychological treatment. This indeed is nothing more than a restatement of our problem. Psychology is not a single science, it is several. However, the fact that we have several relatively distinct psychological sciences does not imply that we have several distinct subject matters to which they are applied. The psychologies may be many yet the mind may still remain one.

If we analyze the various antinomies that underlie the divisions between distinct psychological schools we will realize that the poles of each of these antinomies (which are isolated in the various psychological sciences) actually blend into one another in such a manner as to reveal their mutual interdependence. In this I am following the lead of 
Koch (1983) who held that there are a class of important propositions, of radical significance for psychology, which suggest their contradictions (or contraries) as strongly as they suggest their own affirmation. Let us then reexamine each of the seven antinomies I have outlined with this dialectical view in mind.

(1) Determinism Vs. Free Will: A recognition of the mutual interdependence of determinism and free will begins with Hume's observation that one cannot act freely unless one can assume the regularity of causal effects, i.e. that one's actions will generally bring about one's desired ends. Included in this assumption are all the causal mechanisms that obviously operate within the human body, sustaining life and supporting the very behaviors that we produce volitionally. Further, "freedom", even if it is conceived of as the ability to transcend the causal nexus through an act of will, must embody an element of determinacy (causality) in bringing about the ends it desires, because otherwise both free actions and their effects would be totally random. The very concept of free will is thus dependent upon the concept of determinate causality. However, the reverse is true as well. In order for us to arrive at the cause of a given phenomenon in particular (and the concept of determinate causality in general) we must be able to reason freely about the objects of our experience, in a manner which is completely non-prejudicial and, according to some philosophers, outside the frame of material causality. For example, the conclusion that a certain event $\mathrm{x}$ was caused by another event y cannot be justified on the grounds that certain neurons went off in $m y$ brain (Hampshire, 1971). The only possible justification for a mathematical, scientific, or philosophical proposition (and this includes all conclusions about "causality") is that it was arrived at in the light of reason, a justification which itself implies a certain independence from material causality. Hence the very concept of material causality is itself dependent upon a certain freedom from such causality.

(2) Objectivism vs. Constructivism: The interdependence of these contrasting perspectives becomes evident when we note that the very things (trees, animals, rocks, etc.) which common sense regards as examples of the objective, material world, cannot be comprehended unless they are subsumed under a category or idea. As Hegel points out, even the pointing to a material object or a mere reference to "this" involves us in categorical thinking, and that such thinking inevitably leads to an element of "mind" in all things. On the other hand, the very categories or ideas through which we divide up and cognize the world are themselves dependent upon the existence of concrete examples which subsist independently from the mind. The very concept of the objective or physical implies the constructed or mental and vice versa.

(3) Elementism vs. Holism: The claim that the molar properties of the mind, such as thought, volition, and consciousness are dependent upon and explicable on the basis of molecular units, is itself dependent upon these very molar properties. In other words, reductionism, whether conceived in biological or psychological terms, is dependent upon the acts, thoughts and experiences needed to articulate and verify the reductionist point of view. Further, as any attempt to analyze the mind into its component sensations, cognitions, etc. will reveal, these "particles" of the psyche can only be identified as a part of more global perceptions, thoughts, and acts of consciousness. What enables me to call 
something a sensation, for example, is that it is a part of my ongoing molar experience, say, of "this red chair". The notion of an isolated sensation is itself an abstraction that is dependent upon a more macroscopic point of view. A further illustration of the interdependency of molar and molecular properties, is seen in the fact that it would be impossible to identify the neurobiological components of memory, for example, without the more "molar" notion of memory itself.

At the same time scientific research and reason leads to the conclusion that the mind is completely dependent upon its molecular parts and in no ways contains any "substance" which is over and above the biological, psychological and behavioral units that comprise it. Hence, the "elemental particles" of mind are dependent upon holistic "emergent properties", while at the same time these properties are dependent upon their molecular components.

(4) Public vs. Private mental criteria: The idea that our private, introspective knowledge of our own mental states, moods and feelings is secondary to these states' public or behavioral display originates with such 20th century philosophers as Wittgenstein (1953) and Ryle (1949) and was successfully adopted by the school of psychological behaviorism. Wittgenstein, for example, argued that the very possibility of our having introspective knowledge of our thoughts and feelings is itself dependent upon a process in which we learn to label the thoughts and feelings of ourselves and others on the basis of their publicly observable behavior. Depression, is not primarily when I feel a certain way, but is more fundamentally a way in which I and others act which the community of speakers calls depression. Only after learning the concept behaviorally do we apply mental terms to our own case through introspection. The very notion of an inner mental state is thus necessarily dependent upon a public, behavioral display and language. The reverse, however, is true as well, for my awareness of the existence of certain behavior is itself dependent upon my own (private) experience that this behavior is the same as other behavior that the community labels with a certain mental term. Furthermore, regardless of how a word like "depression" is learned or used, it makes little or no sense to speak of a depression that could not be introspectively experienced. Thus behaviorism and introspection, public and private criteria, which are usually thought to be mutually exclusive ideas, are seen to be mutually dependent notions.

(5) Individualism vs. Collectivism: The mutual interdependence of individual and collective perspectives in psychology follows naturally from the dialectic implicit in the previous antinomy between introspection and behaviorism. There we saw that the very language that we utilize to describe our individual, interior life is dependent upon a community of speakers. (As Wittgenstein put it "there cannot be a private language"). To be an individual self means to be distinguished from and yet be a part of a community. The "other" is essentially implicit in the individual, not only via language, but through a series of struggles, conflicts and identifications which as both Hegel (1977) and Freud recognized, weave the tapestry of the "individual" self. Yet the opposite is obviously true as well; the community or "system" is nothing without its component individual parts, and, indeed, the community is a mere abstraction apart from its representation (and actualization) in the lives of individuals. 
(6) Factualism and Hermeneutics: The antinomy between "factualism" and "hermeneutics" leads to the realization that there are no "facts" of human experience, no "causes" in the life of the mind until they are apprehended and hence interpreted by a human subject. Yet the very notion of interpretation implies a primary datum that must be interpreted, an observation which prompts philosophers to posit a hard reality behind the categories and appearances of the phenomenal world, and which prompted Freud to posit the existence of a latent dream behind the contents of the manifest one. The antinomy of "facts" versus "interpretations" has been hotly debated in the philosophy of science (see Taylor, 1964). It is also silently at work in the current debate around "repressed memory". One question raised by these debates is whether there are indeed memories or even facts without interpretations. What these debates have prompted us to realize, however, is that facts and their interpretations are mutually supportive and interdependent ideas.

(7) (Complete) Knowability vs. (an essential) Unknown: The mutual interdependence of knowledge and the unknown is evident from a number of considerations, some of which are quite obvious in nature. One of these is the observation that all knowledge, all science, proceeds, as it were, out of mystery. As Hegel argued, the history of human endeavor is one in which the forest of mystery is continuously pushed back in favor of the clearing of knowledge. With each advance, however, there is an acknowledgment of a further "unknown" which itself then becomes the subject of new investigation, and an awareness that what was once known to be fact, was at least in part, error. Psychologists are all too familiar with the notion that truth itself is a species of "error" which only approximates an ideal. All so-called scientific "truths" of the past and present have been, or will be, revealed to be errors of one form or another.

Further, since the very structure of human awareness limits it to some specific "presence" or content, there is always something, some potential knowledge or mental content, that exists beyond its reach; such content being notable for its "absence", for the fact that it is unknown. On a more psychological level, while the content of consciousness changes from one moment to the next, the general dialectic between "presence" and "absence", between known and unknown always remains. It is thus part of the concept of consciousness or mind that there is something, not yet specified, that is or absent, beyond awareness or unconscious. Hence it is part of the very concept of the known that there is yet something unknown or undiscovered. Yet what is unknown can only be articulated against a background of what (is believed) to be known.

Further insight into the interdependence of the known and the unknown can be obtained via an analogy from mathematics. An infinite mind, we might surmise, would have no need for mathematical knowledge, for example, for the infinite number of mathematical expressions equal to the number seven. This is because such a mind would comprehend instantaneously the equivalence of all such operations. It is only for a finite intellect that such equivalences (e.g. 4+3, 91/13, 100-93, etc.) must be spelled out. Indeed it is only because of our failure to have perfect mathematical knowledge that the 
detailed system of mathematical knowledge is necessary at all, such system being a tool for the finite mind. By analogy, it can be argued that what we call knowledge is itself predicated upon a failure to know; one who understood the world sub species aeternae would comprehend the totality instantaneously and therefore have no need, whatsoever, for individual facts, theories or knowledge in the human sense of these terms. What we call knowledge is fully dependent upon some things being opaque or unknown.

\section{The Opposite is the Completion}

Though tentative and schematic, the above discussion suggests that in their deep, philosophical, structure the various models of contemporary psychology are actually interdependent. This is because the very philosophical principles which each model or theory regards as axiomatic are dependent upon the very opposing principles which each theory regards as contrary to its own. Like the Mercator and Polar two-dimensional maps of the globe, which must be regarded as complementing and completing one another, the principles of fee will and determinism, private and public criteria, knowledge and the unknown, etc. can be regarded as complementary rather than contradictory or contrary ideas. Put another way, our dialectical analysis of the seven psychological antinomies we have outlined suggests that apparently contrary truths need not be mutually exclusive. As the physicist Neils Bohr held, it is only superficial truths whose opposites are false; the opposites or contrary's of "deep" truths are also true themselves.

But how can this "complementarity of opposites" be understood on the level of psychological theory. How, for example, can one integrate existential with biological psychology? I want to suggest that the solution to the problem here is not so much one of integrating the split between existentialism and biology, but rather in the facilitation of our own ability to move, dialectically, between them, and to retain within our understanding the possibility that what appear to be contrary points of view are in fact, complementary, interdependent and mutually correcting perspectives. Indeed, in psychiatry and clinical psychology, we do this on a daily basis. The biological psychiatrist medicating a patient, is dependent upon the patient's own phenomenological self-report to assess the patient's medication response, and the psychoanalyst treating a depression is dependent upon the patient's publicly observable behavior as an indication of his resistance, transference, etc.

In psychology we must take seriously the notion of an object, i.e. the human mind, which maintains its identity and coherence in spite of being subject to apparently contrary descriptions. This, by the way, is what clinicians frequently ask of their patients in psychotherapy. Patients are, in effect, asked to expand their notions of themselves so that they can tolerate feeling both love and hate towards the same person, so that they can acknowledge being conditioned by their past but at the same time feel free to decide their future, so that they can tolerate a relationship (or a life) that simultaneously feels both untrustworthy and secure, and so they can accept within themselves certain characteristics which they normally regard as reprehensible, etc. This is not the place to explore the idea in detail, but the problem of the multiplicity of psychological theories is analogous to the problem of the multiple self. The "treatment" for each of these multiplicities is effectively the same: i.e. a dialectical expansion of consciousness to 
S. Drob Fragmentation in Contemporary Psychology:

Journal of Humanistic Psychology, Volume 43, No. 4, Fall 2003, 102-123. C 2003 Sage Publications.

tolerate and include opposition and apparent contradiction. Such "treatment", which, in this essay, I have offered with respect to the various psychological schools, is, in effect, the opposite of "dogmatics", the adoption of one point of view to the exclusion of all others. As has often been observed, the phenomena of dogmatism and neurosis have in common a failure of dialectic between opposing perspectives, and hence a rigidified adherence to a single point of view. It is my hope that the analogies and arguments set forth in this essay have provided a certain justification for liberalism and multiperspectivism in psychology. Psychology unified under a single, dogmatic paradigm is an impossible and unlaudable ideal.

\section{References}

Baars, B.J. (1985). The logic of unification, Contemporary Psychology, 30, 340.

Bower, G.H. (1993). The Fragmentation of psychology? American Psychologist, $\underline{48}$, 905907.

Dixon, R.A, (1983). Theoretical proliferation in psychology. A plea for sustained disunity. The Psychological Record 33, 337-40.

Drob, S. (1987). The dilemma of contemporary psychiatry. American Journal of Psychotherapy, $\underline{43}, 54-67$.

Giorgi, A. (1985). Theoretical plurality and unity in psychology. The Psychological Record, $\underline{35}, 177-81$.

Hampshire, S. (1971). Freedom of Mind, in Freedom of Mind and Other Essays. Princeton, N.J.: Princeton University Press.

Hegel, G.W.F. (1977). Phenomenology of the Spirit. (A.V. Miller, Trans.) Oxford: Clarendon Press.

Kimble, G.A, (1984). Psychology's two cultures. American Psychologist, $\underline{39}$, 833-839.

Kitcher, P. (1992). Freud's Dream: A Complete Interdisciplinary Science of Mind. Cambridge: Harvard University Press.

Koch, S. (1981). The nature and limits of psychological knowledge: Lessons of a quarter century qua science. American Psychologist, $\underline{36}, 257-69$.

Kristensen, Kristoffer B. (1997). On What Basis are Evaluations Possible in a Fragmented Psychology. Paper presented at the 1997 Annual Meeting of the American Psychological Association.

Martin, J. (1997). Fragmentation, Hermeneutics, and Liberal Education in Psychology. Paper presented at the 1997 Annual Meeting of the American Psychological Association. 
Journal of Humanistic Psychology, Volume 43, No. 4, Fall 2003, 102-123. C 2003 Sage Publications.

McNally, R. (1992). Disunity in psychology: Chaos or specialization? American Psychologist, 47, 399-413.

Miller, A. and Findlay (1971). J.N. Hegel's Philosophy of Mind. (William Wallace and A.V. Miller Trans. with foreword by J. N. Findlay. Oxford: Clarendon Press.

Ryle, G. (1949). The Concept of Mind. New York: Barnes and Nobles.

Staats, A. (1981). Paradigmatic behaviorism, unified theory, unified theory construction, and the zeitgeist of separatism. American Psychologist, 36, 239-256.

Staats, A.W. (1986). Unified positivism: a philosophy for psychology and the disunified sciences. Theoretical and Philosophical Psychology $\underline{6}, 77-90$.

Staats, A.W. (1991) Unified positivism and unification psychology: Fad or new field? American Psychologist, 46, 899-912.

Taylor, C. (1964). The Explanation of Behavior. London: Routledge Kegan Paul.

Wallace, W. and Findlay, J.N. (1975). Hegel's Logic. (W. Wallace, Trans. with Foreword by J. Findlay.) Oxford: Clarendon Press.

Wittgenstein, L. (1953). Philosophical Investigations. (G. Anscombe, Tans.) New York: MacMillan Publishing Company.

${ }^{1}$ Jung, however, is also of interest for his adoption of the (Hegelian) point of view that opposite viewpoints within (and about) the psyche do not exclude one another, a position that will become critical to our resolution of psychology's dilemma.

*Psychoanalysis, as has been suggested by Ricouer (1970) and others can best be understood as comprising two points of view, the first corresponding to psychoanalytic theory (the metapsychology) and the second to its clinical practice (see Drob, 1987). 